\title{
The Influence of Anaerobic Digestion on Selected Heavy Metals Fractionation in Sewage Sludge
}

\author{
Magdalena Zdeb ${ }^{1 *}$, Małgorzata Pawłowska', Justyna Pacan ${ }^{1}$ \\ 1 Lublin University of Technology, Faculty of Environmental Engineering, ul. Nadbystrzycka 40B, 20-618 Lublin, \\ Poland \\ * Corresponding author's e-mail: m.zdeb@pollub.pl
}

\begin{abstract}
Rising efficiency of wastewater purification systems causes an increase in the amounts of sewage sludge. Its land application is economically attractive because of low cost and high efficiency. Using sewage sludge in agriculture is one of the most preferred ways of its disposal. Only stabilized sludge and containing permissible concentrations of heavy metals can be used for this purpose. The heavy metals introduction into the environment may cause a potential problem for public health, especially when they percolate from soil to plants or groundwater. Therefore, the concentrations of heavy metals in sludge intended for agriculture are regulated. Determination of total content of heavy metals in digested sludge is not sufficient for the evaluation of a potential risk to the environment. The mobility and toxicity of heavy metals depend strongly on their specific chemical forms. The concentrations of particular heavy metal fractions are the most important parameters, which should be examined in order to estimate the influence of sludge on the environment. The aim of an article was to evaluate the influence of anaerobic digestion on the concentration and variability of chemical forms of selected heavy metals $(\mathrm{Cr}, \mathrm{Cu}, \mathrm{Ni}, \mathrm{Pb}, \mathrm{Zn})$ in the sewage sludge coming from a municipal wastewater treatment plant in Pulawy (Poland). The content of particular forms of heavy metals in raw and digested sewage sludge was determined by means of the BCR (Community Bureau of Reference) method. The BCR method enables separating four fractions of heavy metals: exchangeable, reducible, oxidizable and residual. The results obtained after analyzing raw sludge showed that the majority of the analyzed heavy metals were predominantly associated with the oxidizable and residual fractions. Only in the case of $\mathrm{Zn}$, the reducible form constituted a greater part. In the case of digested sludge, all studied heavy metals exhibited the most dominant oxidizable and residual fractions; however, the percentages of particular fractions were different than in raw sludge. It was noticed that all heavy metals concentrations were higher in digested sludge in comparison to sludge before anaerobic digestion. The content of heavy metals in the analyzed materials did not exceed the admissible Polish levels for the sludge intended for the agricultural use.
\end{abstract}

Keywords: sewage sludge, anaerobic digestion, heavy metals, sequential chemical extraction

\section{INTRODUCTION}

Improvement in the efficiency of wastewater purification causes an increase in the amounts of generated sewage sludge. Wastewater treatment plants produce millions of tons of residual sludge worldwide every year. More and more new techniques of reducing the sludge amounts are used nowadays [Stephenson et al., 2000; Di Iaconi et al., 2005; Aulenta et al., 2008]. Rational sludge management is one of the main problems of the world, especially because of ecological and economical reasons. The sewage sludge disposal is an issue of growing importance, as the costs of sludge treatment and disposal may reach even $60 \%$ of the total operating costs in wastewater treatment plants [Teh et al., 2016].

In recent times, the main ways of sewage sludge disposal are landfilling, incineration and farmland application [Hernandez et al., 2011]. Sludge is regarded as a potential source of nutrients, minerals and organic matter. Raw sludge is characterized by an unpleasant odour, because it contains many noxious compounds, such as 
$\mathrm{NH}_{3}$ and $\mathrm{H}_{2} \mathrm{~S}$ [Cukjati et al., 2012]. It also contains the microorganisms which might be harmful to human health. Therefore, the stabilization of sludge is necessary. The application of modern technologies of sludge treatment transforms it into chemically stable and sanitary safe material. It results in more frequent and popular usage of sewage sludge for the agricultural purposes, especially when its landfilling is banned [Braguglia et al., 2012].

The land application of sewage sludge is economically attractive because of its low cost and high efficiency. The agricultural utilization of sewage sludge (as a valuable fertilizer or soil amendment) plays an important role in many countries and urban areas, as the sludge has soilforming and fertilising properties. It contains the substances needed by plants for growth (nitrogen, phosphorus, calcium, magnesium, potassium, organic matter). One of the main features of sewage sludge preventing its use for agricultural purposes is high heavy metals content. Introduction of heavy metals into the natural environment may cause a potential problem for the public health, especially when they percolate to plants or groundwater [Hanay et al., 2008]. The total heavy metals concentration in the digested sludge is not a reliable indicator of their bioavailability and does not constitute a basis for the evaluation of potential hazardous effects on the environment. The mobility and toxicity of heavy metals strongly depend on their specific chemical forms. The content of particular heavy metal fractions is the most important parameter, which should be studied in order to estimate the influence of sludge on the environment [Fuentes et al., 2004; Wang et al., 2006]. The BCR (Community Bureau of Reference) method of a sequential chemical extraction of heavy metals can be useful in determination of heavy metals forms. It enables separating four fractions of heavy metals: exchangeable (containing the elements, which are accessible and bound to carbonates), reducible (containing the elements bound to amorphous iron and manganese oxides), oxidizable (containing the metal-organic and sulphide fractions) and residual (containing the elements bound to silicates [Han et al., 2003; Szumska and Gworek, 2009; Latosińska and Gawdzik, 2012]). First two fractions are believed to be mobile, other two - temporarily immobilized. This method was originally developed for the analysis of heavy metals in the samples of bottom sediment taken from natural water environment
[Ure et al., 1993]. Recently, this procedure has been successfully applied to the extraction of heavy metals in bottom sediments, soils and sludge samples [Dąbrowska, 2016].

The aim of the article was to evaluate an influence of anaerobic digestion on the concentration and variability of chemical forms of selected heavy metals $(\mathrm{Cr}, \mathrm{Cu}, \mathrm{Ni}, \mathrm{Pb}, \mathrm{Zn})$ in the sewage sludge coming from a municipal wastewater treatment plant in Pulawy (Poland).

\section{MATERIALS AND METHODS}

\section{Sludge characteristic}

Raw and digested sludge, coming from a wastewater treatment plant in Pulawy, near Lublin (Poland) were used for the study. Raw sludge was a mixture of primary sludge, excessive thickened sludge and municipal waste biofraction coming from a Municipal Waste Treatment Plant at the volume ratio of 75:25 (primary and excessive sludge:biofraction). The samples of raw sludge were taken from technological line of wastewater treatment plant before anaerobic digester. The digested sludge samples were taken after the digester. The parameters of raw and digested sludge are shown in Table 1.

\section{BCR method}

The BCR (Community Bureau of Reference) method of the sequential chemical extraction for estimating particular forms of heavy metals was used. According to this method, four fractions of particular elements were separated: exchangeable, reducible, oxidizable and residual. The procedure of the BCR method is shown in Figure 1.

The sludge samples were dried at ambient temperature, homogenized in porcelain mortar and sieved through a sieve with a mesh diameter $0.1 \mathrm{~mm}$. The extraction of particular forms of heavy metals was conducted in two repetitions of each type of sludge (raw and digested).

Table 1. Characteristic of raw and digested sludge (average values and standard deviations)

\begin{tabular}{|c|c|c|}
\hline Parameter & Raw sludge & Digested sludge \\
\hline $\mathrm{TS}\left[\mathrm{g} \mathrm{kg}^{-1}\right]$ & $30.5 \pm 0.17$ & $14.9 \pm 0.14$ \\
\hline $\mathrm{VS}\left[\mathrm{g} \mathrm{kg}^{-1}\right]$ & $27.68 \pm 0.35$ & $9.18 \pm 0.15$ \\
\hline $\mathrm{pH}[-]$ & $6.81 \pm 0.06$ & $7.37 \pm 0.05$ \\
\hline
\end{tabular}




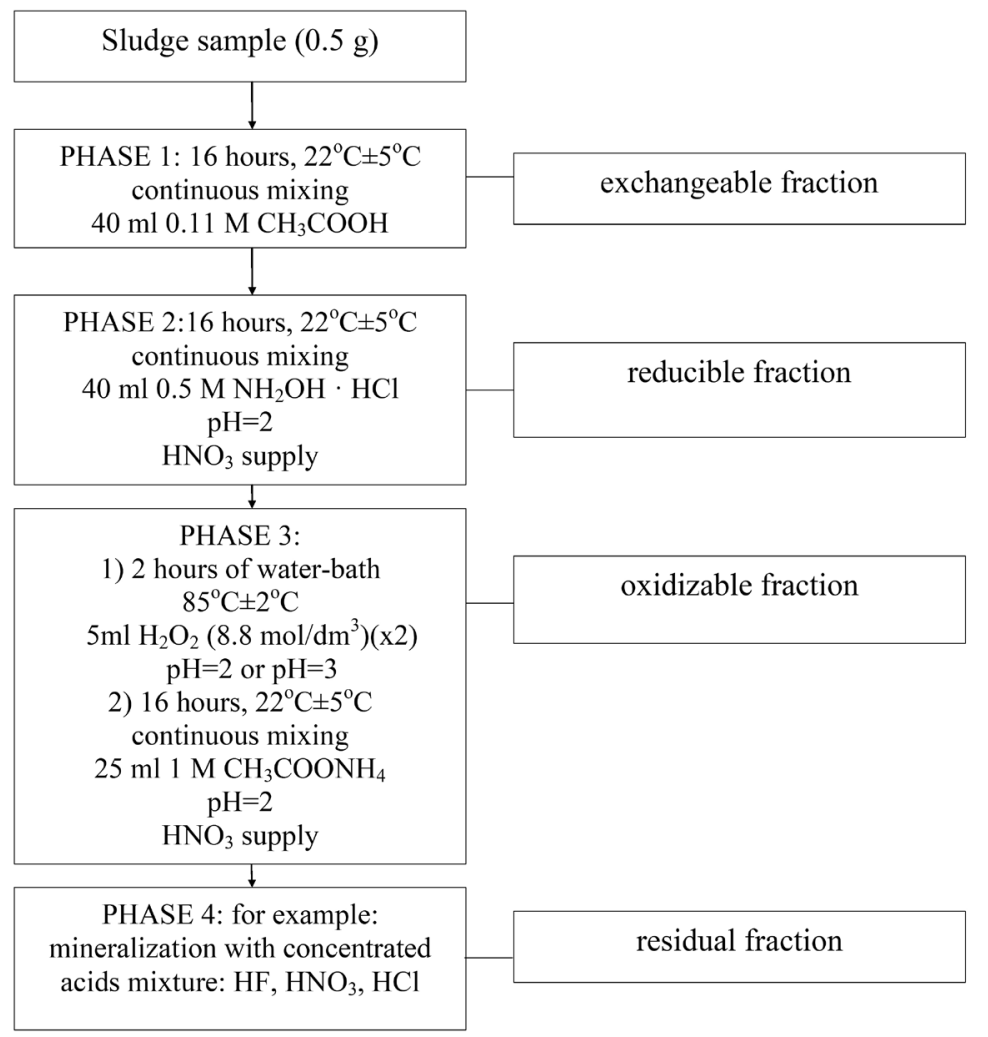

Figure 1. Scheme of the sequential chemical extraction procedure by BCR method

In turn, the sludge samples were treated with chemical reagents of rising aggressiveness $\left(0.11 \mathrm{M} \mathrm{CH}_{3} \mathrm{COOH}, 0.5 \mathrm{M} \mathrm{NH} \mathrm{NH}_{2} \mathrm{OHCl}\right.$, $8.8 \mathrm{M} \mathrm{H}_{2} \mathrm{O}_{2}, 1 \mathrm{M} \mathrm{CH}_{3} \mathrm{COONH}_{4}$ and mixtures of concentrated acids $\mathrm{HNO}_{3}$ and $\mathrm{HCl}$ ). Four phases of the sequential chemical extraction by BCR method were conducted. The subsequent stage of research was to evaluate the total content of studied heavy metals, in order to verify its sum, obtained in individual fractions analysis.

\section{Analytical methods}

In the samples of raw and digested sludge, total solids (TS), volatile solids (VS) and $\mathrm{pH}$ were determined in duplicates. TS were determined after drying samples for $24 \mathrm{~h}$ at $105^{\circ} \mathrm{C}$ in SUP-4 Wamed drying chamber (water evaporation). VS were determined after burning the dried samples to ashes for $24 \mathrm{~h}$ at $550^{\circ} \mathrm{C}$ in a FCF $2,5 \mathrm{~S}$ muffle furnace (Czylok). The sludge samples $\mathrm{pH}$ were analyzed in the supernatant obtained after the sludge spinning in Med Instruments type MPW-350 spin-dryer at the speed of 3700 rotations/minute over 10 minutes. The measurements of $\mathrm{pH}$ were performed using multifunctional meter Eutech Instruments type PCD 6500.
Quantification of heavy metal concentrations in raw and digested sludge and in the sludge samples taken from particular phases of the sequential chemical extraction was performed using JY 238 Ultrace ICP Spectrometer with radical plasma (Horiba Jobin Yvon). The sludge samples were mineralized in acid environment in Anton Paar microwave device before the analysis.

\section{Statistical analysis}

All analyses were conducted in duplicate. The means and standard deviations of the sludge parameters and heavy metals concentrations in the studied materials were calculated.

\section{RESULTS AND DISCUSSION}

\section{Sludge parameters}

TS and VS of raw sludge was $3.05 \%$ and $90.75 \%$ TS, respectively. In the case of digested sludge, these parameters were $1.49 \%$ and $61.6 \%$ TS. Digested sludge was characterized by higher $\mathrm{pH}$, water content and mineral matter content in comparison to raw sludge. According to 
the data shown by Heidrich and Nieścior [1999], the sludge digested with high efficiency is characterized by $\mathrm{pH} 7.2 \div 7.5$, TS content $4 \div 12 \%$ and VS content $45 \div 55 \%$ TS. Hence, the digested sludge from wastewater treatment plant in Pulawy, in the case of $\mathrm{pH}$ can be classified as digested with high efficiency. However, in terms of the VS content, it can be included to digested with medium efficiency. Relatively low TS content in digested sludge probably results from the applied technological solutions of the process and high efficiency of organic matter decomposition.

\section{Total concentration and concentration of particular forms of selected heavy metals in raw and digested sludge}

The analyses of four particular forms of selected heavy metals in sewage sludge were conducted using the BCR method. The average concentrations of these forms in raw and digested sludge are shown in Table 2.

Total concentrations of studied heavy metals in raw and digested sludge were estimated in two ways: obtained after the quantitative analysis of both types of sludge and calculated as a sum of concentrations of particular forms of heavy metals after the sequential chemical extraction. The comparison of these values is presented in Table 3.

As it can be seen, the divergences in results concerning heavy metals concentrations obtained in two ways of determination were not higher than $1 \%$. It was noticed that all heavy metals concentrations were higher in digested sludge in comparison to the sludge before anaerobic digestion. It might be a result of the weight loss of the raw sludge during the anaerobic digestion process.
The configuration of percentage participation of particular heavy metal forms in raw and digested sludge is presented in Figures 2-6.

In most cases, the highest percentages were achieved for the oxidizable and residual fractions, in both raw and digested sludge. It was found that subjecting sludge to anaerobic digestion caused the change in the percentages of particular forms of all studied heavy metals.

The results of experiment show that the temporarily immobilized fractions of $\mathrm{Cr}$ (oxidizable and residual) were the most numerous, according to others, in both: raw and digested sludge (Fig. 2). Scancar et al. [2000], Garcia-Delgado et al. [2007], Dąbrowska [2016] and Tytła [2019] reached the same conclusion. The content of these fractions in the present studies constituted 100\% and $96.4 \%$ of the total $\mathrm{Cr}$ concentration, in raw and digested sludge, respectively. The percentages of the oxidizable and residual fractions in raw sludge were $63.1 \%$ and $36.9 \%$, respectively. In the case of digested sludge, the decrease of the oxidizable fraction content was observed (to $38.3 \%$ ) at a simultaneous increase in the percentage of the residual fraction (to 58.1\%). These results are in line with Tytta [2019] who observed the same relations after analyzing the concentrations of particular heavy metal fractions in seven sampling points of technological line of a wastewater treatment plant. It can be stated that anaerobic digestion caused the transformation of the oxidizable form (poorly available for plants uptake) into the residual form of $\mathrm{Cr}$ (nearly unavailable for plants uptake). As regards other fractions, low percentage (3.6\%) of the exchangeable fraction was observed (only in digested sludge). Probably, it can be a result of chromium ions release from organic connections caused by organic carbon reduction

Table 2. Concentrations of particular forms of selected heavy metals in raw and digested sludge

\begin{tabular}{|c|c|c|c|c|c|}
\hline \multirow{2}{*}{ Heavy metal } & \multirow{2}{*}{$\begin{array}{l}\text { Type of } \\
\text { sludge }\end{array}$} & Exchangeable fraction & Reducible fraction & Oxidizable fraction & Residual fraction \\
\hline & & {$\left[\mathrm{mg} \mathrm{kg} \mathrm{TS}^{-1}\right]$} & {$\left[\mathrm{mg} \mathrm{kg} \mathrm{TS}^{-1}\right]$} & {$\left[\mathrm{mg} \mathrm{kg} \mathrm{TS}^{-1}\right]$} & {$\left[\mathrm{mg} \mathrm{kg} \mathrm{TS}^{-1}\right]$} \\
\hline \multirow{2}{*}{$\mathrm{Cr}$} & raw & n.d. & n.d. & $5.79 \pm 1.01$ & $3.38 \pm 0.94$ \\
\hline & digested & $2.01 \pm 0.87$ & n.d. & $21.48 \pm 1.3$ & $32.61 \pm 0.89$ \\
\hline \multirow{2}{*}{$\mathrm{Cu}$} & raw & $3.44 \pm 0.74$ & $2.62 \pm 0.60$ & $60.98 \pm 1.45$ & $16.32 \pm 0.98$ \\
\hline & digested & $2.68 \pm 0.34$ & $2.01 \pm 0.73$ & $114.77 \pm 0.93$ & $43.67 \pm 1.58$ \\
\hline \multirow{2}{*}{$\mathrm{Ni}$} & raw & $1.97 \pm 0.66$ & $1.42 \pm 0.99$ & $4.26 \pm 1.66$ & $2.21 \pm 1.01$ \\
\hline & digested & $0.67 \pm 0.45$ & $2.68 \pm 1.23$ & $10.07 \pm 1.70$ & $9.86 \pm 0.88$ \\
\hline \multirow{2}{*}{$\mathrm{Pb}$} & raw & n.d. & $1.31 \pm 0.33$ & $5.36 \pm 0.44$ & $3.57 \pm 0.92$ \\
\hline & digested & n.d. & $8.72 \pm 1.20$ & $40.07 \pm 1.43$ & $32.68 \pm 1.33$ \\
\hline \multirow{2}{*}{$\mathrm{Zn}$} & raw & $117.70 \pm 1.91$ & $325.03 \pm 0.87$ & $260.33 \pm 0.66$ & $42.25 \pm 0.53$ \\
\hline & digested & $212.08 \pm 0.57$ & $89.93 \pm 1.20$ & $504.70 \pm 0.82$ & $798.10 \pm 1.89$ \\
\hline
\end{tabular}

n.d. - not detected 
Table 3. Comparison of total concentrations of selected heavy metals in raw and digested sludge

\begin{tabular}{|c|c|c|c|}
\hline \multirow{2}{*}{ Heavy metal } & \multirow{2}{*}{ Type of sludge } & \multicolumn{2}{|c|}{ Total concentration } \\
\cline { 3 - 4 } & raw & $\begin{array}{c}\text { Sum of concentrations of particular } \\
\text { fractions [mg kg TS }\end{array}$ & $\begin{array}{c}\text { Quantitative analysis } \\
{\left[\mathrm{mg} \mathrm{kg} \mathrm{TS}^{-1}\right]}\end{array}$ \\
\hline \multirow{2}{*}{$\mathrm{Cr}$} & digested & 9.17 & $9.2 \pm 1.23$ \\
\cline { 2 - 4 } & raw & 56.19 & $56.4 \pm 1.35$ \\
\hline \multirow{2}{*}{$\mathrm{Cu}$} & digested & 83.36 & $85.2 \pm 0.98$ \\
\cline { 2 - 4 } & raw & 163.13 & $161.7 \pm 1.97$ \\
\cline { 2 - 4 } $\mathrm{Ni}$ & digested & 9.86 & $9.7 \pm 0.99$ \\
\cline { 2 - 4 } & raw & 23.28 & $23.5 \pm 0.56$ \\
\cline { 2 - 4 } & digested & 10.24 & $10.3 \pm 1.76$ \\
\hline \multirow{2}{*}{$\mathrm{Zn}$} & raw & 81.47 & $81.5 \pm 1.87$ \\
\cline { 2 - 4 } & digested & 745.31 & $745.6 \pm 1.93$ \\
\hline
\end{tabular}

during anaerobic digestion. The concentrations of reducible fractions in raw and digested sludge and the exchangeable fraction of $\mathrm{Cr}$ in raw sludge were under the limit of quantification.

The most noticeable concentrations of the $\mathrm{Cu}$ forms were observed for the oxidizable and residual fractions (Fig. 3). The percentages of these forms were as follows: $73.1 \%$ and $19.6 \%$ for raw sludge and $70.4 \%$ and $26.8 \%$ for the digested sludge. Participation of the oxidizable $\mathrm{Cu}$ fraction was in the range presented by ObarskaPempkowiak et al. [2003] who noted its percentage from $32 \%$ to $78 \%$ for the sludge taken from different points of wastewater treatment plant. Alvarez et al. [2002] observed the percentages of oxidizable $\mathrm{Cu}$ fraction ranging from 80 to $82 \%$. The highest percentages of immobile $\mathrm{Cu}$ fractions in raw sewage sludge were also found by Dąbrowska [2016], Łukowski [2017], Karwowska and Dąbrowska [2017] and Tytta [2019]. As for the mobile fractions of $\mathrm{Cu}$ in raw sludge, the percentages of the exchangeable and reducible forms were $4.2 \%$ and $3.1 \%$, respectively. In the digested sludge, a reduction in the percentages of these fractions was observed, to $1.6 \%$ and $1.2 \%$, respectively. It can be stated that subjecting the sludge to anaerobic digestion caused a decrease in the concentration of the fractions with high bioavailability by a simultaneous increase of nearly unavailable residual fraction.

In the case of $\mathrm{Ni}$, the highest concentrations of oxidizable and residual fractions were observed, for both raw and digested sludge (Fig. 4). The obtained results are in line with Gawdzik et al. [2015], Karwowska and Dąbrowska [2017] and Łukowski [2017] who also found predomination of immobile Ni fractions in sewage sludge. The percentages of the oxidizable fraction in both types of sludge were unchanged (43.2\%). The highest variability of particular fractions concentrations in raw and digested sludge was noted for the exchangeable and residual fractions. Subjecting the

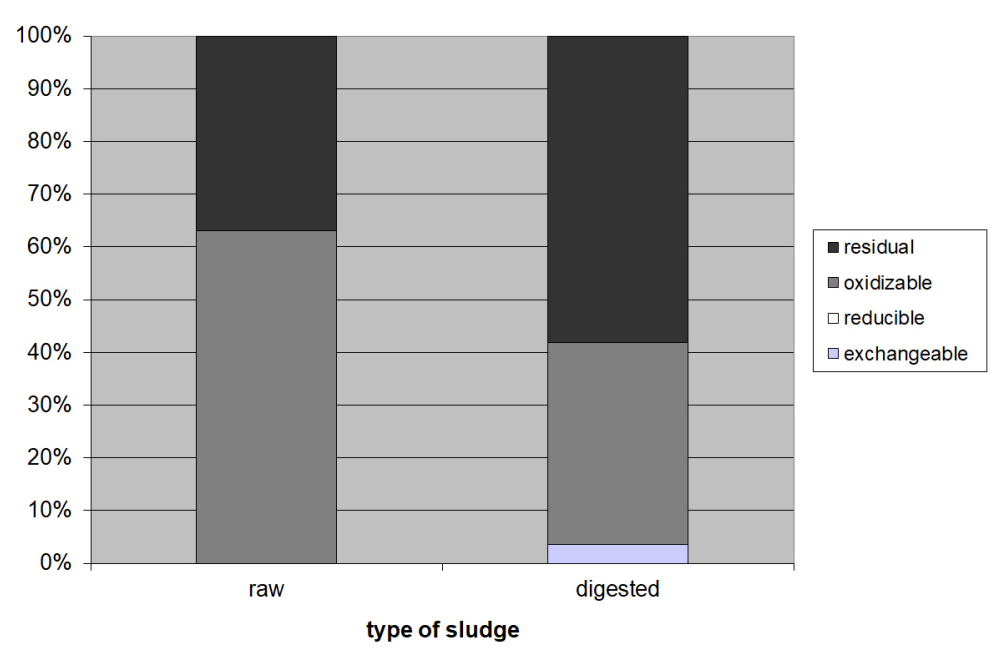

Figure 2. Percentages of particular fractions in the total content of $\mathrm{Cr}$ in raw and digested sludge 


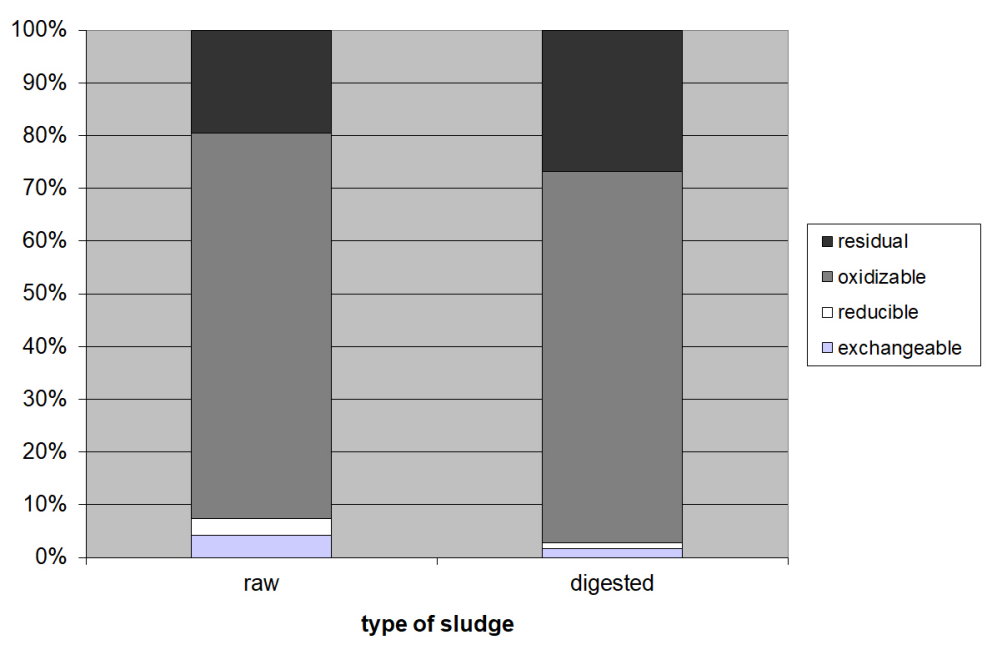

Figure 3. Percentages of particular fractions in the total content of $\mathrm{Cu}$ in raw and digested sludge

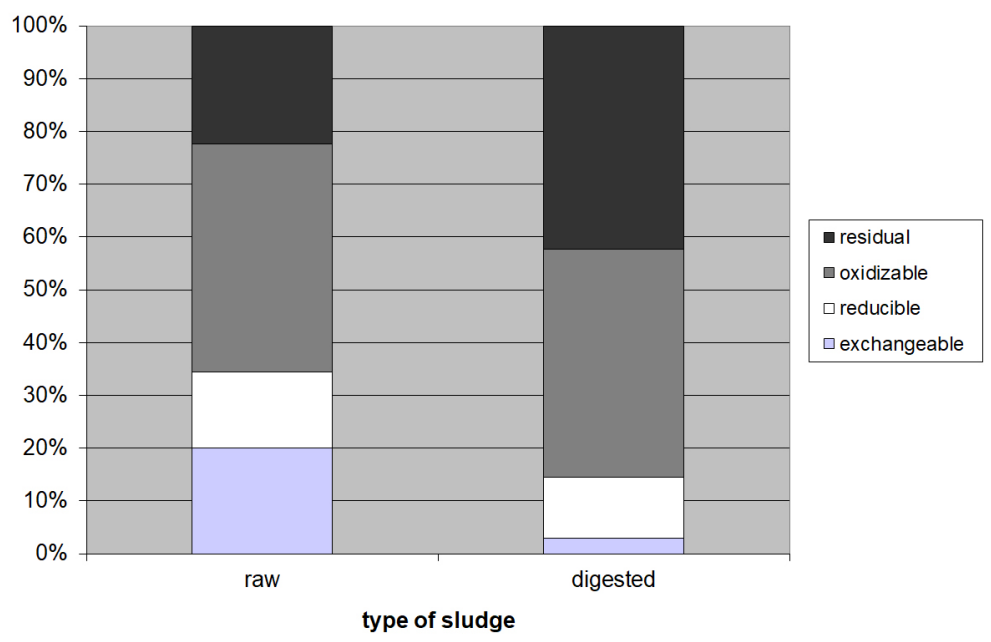

Figure 4. Percentages of particular fractions in the total content of $\mathrm{Ni}$ in raw and digested sludge

sludge to anaerobic digestion caused a decrease in the amount of the exchangeable and reducible fraction, from 20.0 to $2.9 \%$ and from $14.4 \%$ to $11.5 \%$, respectively. Similar relations were noted by Tytla et al. [2016]. At the same time, a considerable increase in the concentration of the residual fraction was observed (from 22.4 to $42.4 \%$ ). The percentages of particular Ni fractions shown in present study are in accordance with the results presented by Alvarez et al. [2002] who studied the content of heavy metals fractions in four types of sludge: primary sludge, secondary sludge, dewatered and digested sludge and compost.

From all studied particular fractions of $\mathrm{Pb}$, the highest percentages were noted for oxidizable and residual fractions for both: raw and digested sludge (Fig. 5). The content of these fractions constituted $87.2 \%$ and $89.3 \%$ of its total concentration, in raw and digested sludge, respectively. The concentrations of the exchangeable $\mathrm{Pb}$ fraction in both types of sludge were under the limit of quantification. The share of the reducible $\mathrm{Pb}$ forms were 12.8 and $10.7 \%$ for raw and digested sludge, respectively. The most significant influence of anaerobic digestion was observed in the variability of the residual fraction, the percentage of which increased by $5.2 \%$ as a result of the conducted process. It correlates with the relation observed by Tytla [2019]. Low concentrations of the mobile $\mathrm{Pb}$ fractions (exchangeable and reducible), along with high content of temporarily immobilized fractions (oxidizable and residual) presented in this study are in line with Alvarez et al. [2002] and Obarska-Pempkowiak et al. [2003].

The percentages of particular $\mathrm{Zn}$ forms were highly variable in the two examined types of sludge. In the case of raw sludge, the 


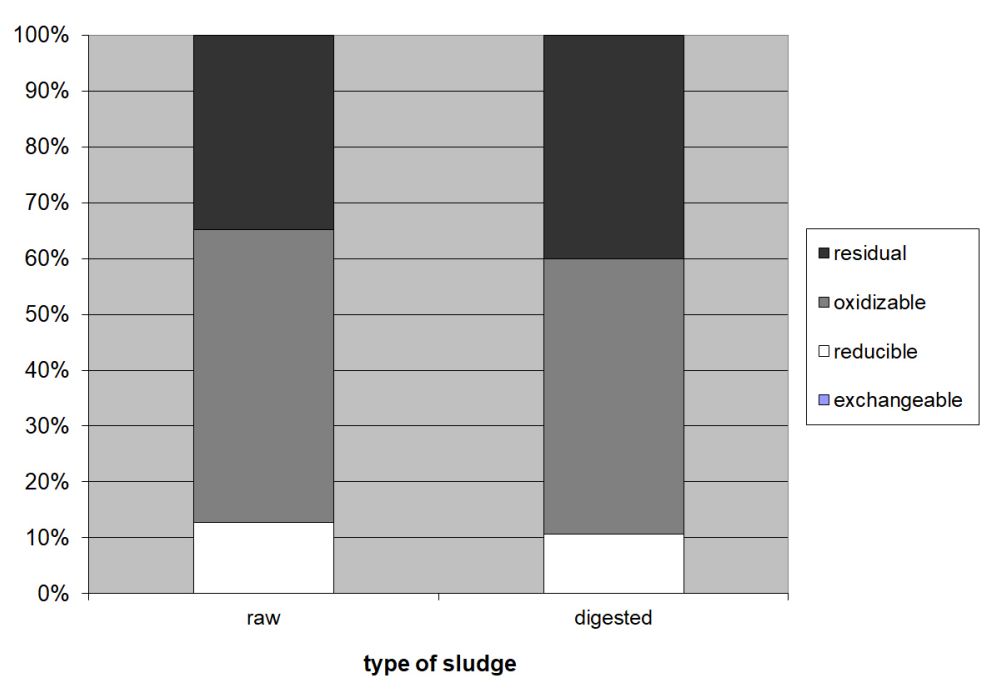

Figure 5. Percentages of particular fractions in the total content of $\mathrm{Pb}$ in raw and digested sludge

highest value was noted for the reducible fraction $(43.6 \%)$ while for digested sludge the highest percentage was observed for the residual fraction (49.8\%). A slight decrease was observed in the percentages of the exchangeable $\mathrm{Zn}$ fraction in sludge before and after anaerobic digestion, from 15.8 and $13.2 \%$. The same tendency for this fraction of $\mathrm{Zn}$ was noted by Tytła et al. [2016]. The percentage of the oxidizable fraction also decreased after anaerobic digestion (from 34.9 to $31.4 \%$ ). As it can be seen from Figure 6., the highest variability of percentages in raw and digested sludge was observed for the reducible and residual fractions. Subjecting the sludge to anaerobic digestion caused a significant decrease in the percentages of the reducible fraction, from 43.6 to $5.6 \%$. Conversely, in the case of the residual fraction, a significant increase of percentages was observed (from 5.7 to $49.8 \%$ ).
Similar changes in the content of the reducible and residual fraction after sludge stabilization were observed by Tytła et al. [2016]. It can be stated that anaerobic digestion caused a reduction of the percentages of mobile fractions and a rise in the percentages of the temporarily immobilized fractions, especially the residual fraction. Alvarez et al. [2002] and Obarska-Pempkowiak et al. [2003] arrived at the same conclusions.

\section{CONCLUSIONS}

The study involved determining the total concentration of $\mathrm{Cr}, \mathrm{Cu}, \mathrm{Ni}, \mathrm{Pb}, \mathrm{Zn}$ and their chemical forms in the sewage sludge before and after anaerobic digestion. The sludge samples were taken from a municipal wastewater treatment plant in Pulawy (Poland).

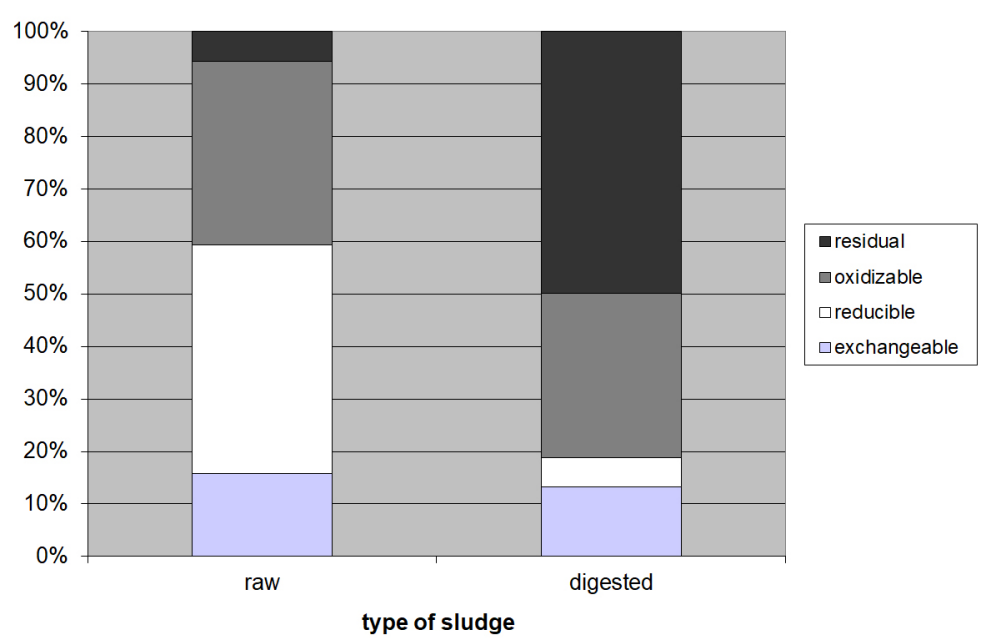

Figure 6. Percentages of particular fractions in the total content of $\mathrm{Zn}$ in raw and digested sludge 
On the basis of the obtained results it was found that the studied sludge parameters are comparable to the general characteristic of municipal sludge produced in Poland. The digested sludge from a wastewater treatment plant in Pulawy can be classified as digested with medium efficiency. The results of the sequential chemical extraction showed that the studied heavy metals in raw sludge were found mainly in the oxidizable and residual forms (considered to be temporarily immobilized). The oxidizable fraction was the most dominant for $\mathrm{Cr}, \mathrm{Cu}, \mathrm{Ni}$ and $\mathrm{Pb}$. $\mathrm{Zn}$ was the exception - its reducible fraction constituted the greater part. It was observed that subjecting sludge to anaerobic digestion caused the variation both in the basic physicochemical parameters of sludge and the content of particular chemical forms of the studied heavy metals. It was noticed that all heavy metal concentrations were higher in digested sludge in comparison to the sludge before anaerobic digestion. It might be a result of the weight loss of the raw sludge during the anaerobic digestion process. From all studied metals, $\mathrm{Zn}$ and $\mathrm{Cu}$ were the most abundant in both types of sludge. The content of heavy metals in the analyzed material did not exceed the permissible Polish levels for the sludge intended for the agricultural use. As a result of anaerobic digestion, the mobile fractions of heavy metals (exchangeable and reducible) were mainly transformed into stable forms regarded as unavailable for plant uptake. The heavy metals mobility in raw sludge changed in the following order: $\mathrm{Zn}>\mathrm{Ni}>\mathrm{Pb}>\mathrm{Cu}>\mathrm{Cr}$ and in digested sludge: $\mathrm{Zn}>\mathrm{Ni}>\mathrm{Pb}>\mathrm{Cr}>\mathrm{Cu}$. Prevalence of immobile fractions over the mobile ones seems to be positive concerning migration of those heavy metals from sludge into the environment and bioaccumulation in living organisms.

\section{REFERENCES}

1. Álvarez E.A., Mochón M.C., Jiménez Sánchez J.C., Ternero Rodríguez M. 2002. Heavy metal extractable forms in sludge from wastewater treatment plants. Chemosphere, 47(7), 765-775.

2. Aulenta F., Canosa A., Majone M., Panero S., Reale P., Rossetti S. 2008. Trichloroethene dechlorination and $\mathrm{H} 2$ evolution are alternative biological pathways of electric charge utilization by a dechlorinating culture in a bioelectrochemical system. Environmental Science \& Technology, 42 (16), 6185-6190.

3. Braguglia C.M., Gianico A., Mininni G. 2012.
ROUTES: innovative solutions for municipal sludge treatment and management. Reviews in Environmental Science and Biotechnology, 11, 11-17.

4. Cukjati N., Zupančič G.D., Roš M., Grilc V. 2012. Composting of anaerobic sludge: An economically feasible element of a sustainable sewage sludge management. Journal of Environmental Management, 106, 48-55.

5. Dąbrowska L. 2016. Fractionation of heavy metals in bottom sediments and sewage sludges using sequential extraction. Ecological Chemistry and Engineering A., 23(1), 63-75.

6. Di Iaconi C., Ramadori R., Lopez A., Passino R. 2005. Hydraulic shear stress calculation in a sequencing batch biofilm reactor with granular biomass. Environmental Science \& Technology, 39, 889-894.

7. Fuentes A., Lloren M., Saez J., Soler A., Aguilar M.I., Ortuno J.F., Meseguer V.F. 2004. Simple and sequential extractions of heavy metals from different sewage sludge. Chemosphere, 54, 1039-1047.

8. García-Delgado M., Rodríguez-Cruz M.S., Lorenzo L.F., Arienzo M., Sánchez-Martín M.J. 2007. Seasonal and time variability of heavy metal content and of its chemical forms in sewage sludges from different wastewater treatment plants. Science of The Total Environment, 382(1), 82-92.

9. Gawdzik A., Gawdzik J., Gawdzik B., Gawdzik A. 2015. New indices determining heavy metals migration in a sewage sludge. Ecological Chemistry and Engineering S., 22(4), 637-644.

10. Han F.X., Banin A., Kingery W.L., Triplett G.B., Zhou L.X., Zheng S.J. 2003. New approach to studies of heavy metal redistribution in soil. Advances in Environmental Research, 8, 113-120.

11. Hanay Ö., Hasar H., Kocer N.N., Aslan S. 2008. Evaluation for agricultural usage with speciation of heavy metals in a municipal sewage sludge. Bulletin of Environmental Contamination and Toxicology, $81,42-46$.

12. Heidrich Z., Nieścior A. 1999. Stabilizacja beztlenowa osadów ściekowych. Wodociągi i kanalizacja. Monografie Polskiego Zrzeszenia Inżynierów i Techników Sanitarnych, 4, Warszawa.

13. Hernandez A.B., Ferrasse J.H., Chaurand P., Saveyn H., Borschneck D., Roche N. 2011. Mineralogy and leachability of gasified sewage sludge solid residues. Journal of Hazardous Materials, 191(1-3), 219-227.

14. Karwowska B., Dąbrowska L. 2017. Bioavailability of heavy metals in the municipal sewage sludge. Ecological Chemistry and Engineering A., 24(1), 75-86.

15. Latosińska J., Gawdzik J. 2012. The effect of incineration temperatures on mobility of heavy metals in 
sewage sludge ash. Environment Protection Engineering, 38(3), 31-44.

16. Łukowski A. 2017. Fractionation of selected heavy metals $(\mathrm{Zn}, \mathrm{Ni}, \mathrm{Cu})$ in municipal sewage sludges from Podlasie Province. Journal of Ecological Engineering, 18(3), 133-139.

17. Obarska-Pempkowiak H., Butajło W., Staniszewski A. 2003. Możliwości przyrodniczego wykorzystania osadów ściekowych ze względu na zawartość metali ciężkich. Inżynieria i Ochrona Środowiska, 2(7), 179-184.

18. Scancar J., Milacic R., Strazar M., Burica O. 2000. Total metal concentrations and partitioning of $\mathrm{Cd}$, $\mathrm{Cr}, \mathrm{Cu}, \mathrm{Fe}, \mathrm{Ni}$ and $\mathrm{Zn}$ in sewage sludge. Science of The Total Environment, 250(1-3), 9-19.

19. Stephenson T., Judd S., Jefferson B., Brindle K. 2000. Membrane bioreactors for wastewater treatment. IWA Publishing, London.

20. Szumska M., Gworek B. 2009. Metody oznaczania frakcji metali ciężkich w osadach ściekowych. Ochrona Środowiska i Zasobów Naturalnych, 41, 42-63.

21. Teh C.Y., Budiman P.M., Shak K.P.Y., Wu T.Y. 2016. Recent advancement of coagulation-flocculation and its application in wastewater treatment. Industrial\&Engineering Chemistry Research, 55(16), 4363-4389.

22. Tytła M. 2019. Assessment of heavy metal pollution and potential ecological risk in sewage sludge from municipal wastewater treatment plant located in the most industrialized region in Poland - case study. International Journal of Environmental Research and Public Health, 16(13), 2430.

23. Tytła M., Widziewicz K., Zielewicz E. 2016. Heavy metals and its chemical speciation in sewage sludge at different stages of processing. Environmental Technology, 37(7), 899-908.

24. Ure A.M., Quevauviller P., Mantau H., Griepink B. 1993. Speciation of heavy metals in soils and sediments. An account of the improvement and harmonization of extraction techniques undertaken under the auspices of the BCR of the Commision of the European Communities. International Journal of Environmental Analytical Chemistry, 51, 135-151.

25. Wang C., Li C.X., Ma H.T., Qian J., Zhai J.B. 2006. Distribution of extractable fractions of heavy metals in sludge during the wastewater treatment process. Journal of Hazardous Materials, 137, 1277-1283. 